\title{
Influence of Pier Settlement on Structural Stress of Longitudinal Connected Track in High-Speed Railways
}

\author{
Hui Fang (i) \\ State Grid Chongqing Electric Power Research Institute, Chongqing, China \\ Correspondence should be addressed to Hui Fang; fanghui99@126.com
}

Received 22 February 2020; Accepted 28 April 2020; Published 22 May 2020

Academic Editor: Eric M. Lui

Copyright $\odot 2020$ Hui Fang. This is an open access article distributed under the Creative Commons Attribution License, which permits unrestricted use, distribution, and reproduction in any medium, provided the original work is properly cited.

\begin{abstract}
Pier settlement is unavoidable in the construction and operation of high-speed railways. This paper presents a work on the influence of pier settlement on additional structural stress of longitudinal connected track (LCT). First of all, the generation mechanism of additional structural stress of LCT caused by pier settlement is described in detail. On this basis, the deformation of LCT caused by pier settlement is analytically deduced and a dynamic model of high-speed train-LCT-bridge coupled system considering pier settlement is established based on the train-track-bridge dynamic interaction theory, adopting which the additional structural stresses of LCT are discussed from static and dynamic perspectives. Results show that pier settlement has a great influence on the stability of LCT. Additional tensile stresses of LCT appear at settlement pier location and two adjacent pier locations. Tensile stresses on top surface of slab and on bottom surface of base should be paid attention to. The behaviors of LCT at adjacent pier locations cannot be ignored in studying the influence of pier settlement on the system. To ensure the stability of LCT and running performance of train, the control value of pier settlement is suggested to be $10.5 \mathrm{~mm}$ from the static and dynamic perspectives in practical engineering.
\end{abstract}

\section{Introduction}

Longitudinal connected track (LCT) is a kind of ballastless track widely adopted in high-speed railways around the world, such as the CRTS II slab track in China [1] and the Bögl slab track in Germany [2]. Compared with other kinds of track structures used in high-speed railways, LCT is a special one because the slabs are connected in the longitudinal direction. Additional structural stresses are easily induced in the track structures subject to bridge deformation, especially pier settlement [3]. These settlement-induced structural stresses may damage the concrete slab and base and finally threaten the running safety of high-speed trains. Hence special attention should be paid to LCT under pier settlement to ensure the safe and reliable operation of highspeed railway.

Mechanical behaviors of LCT are hot research topics in recent years, and many beneficial conclusions have been reached. For instance, Sun et al. [4] carried out a numerical analysis of stress and deflection responses of the CRTS II track system using SAP 2000. Wang et al. [5] established an integral finite element model of jointless turnout (crossover)-track slabbridge-pier taking the LCPBT system on LeiDa Bridge and researched the proper setting length of the rubplate in this structure. Tarifa et al. [6] presented a full-scale experimental work to investigate the development process of crack on concrete slab, in which the sine load was used. Adopting a nonlinear constitutive law at the interface, a 3D finite element model was built by Zhu and Cai to investigate the interface damage that occurred between the slab and CA mortar layer under temperature and vehicle loads [7]. Powrie et al. [8] presented results of finite element analyses carried out to investigate the stress changes experienced by an element of soil beneath a ballasted railway track during train passage. In this work, the effects of element location, the initial in situ stress state of the soil, and the elastic parameters used to characterize its behavior were investigated, and the modelling of the stress paths in a cyclic hollow cylinder apparatus was also discussed. Chen et al. analyzed track stresses and vehicle dynamic responses in train-track-bridge system with pier settlement and determined 
the pier settlement safe value for high-speed railways with CRTS II slab tracks $[1,9,10]$. Except these studies, Brenschede [11], Esveld [12], and Yen and Lee [13] have also proposed valuable models and conclusions. However, in these existing studies, the additional structural stress of LCT caused by pier settlement attracts few attentions, and the generation mechanism of additional structural stress is not well revealed.

Aiming at this issue, this work presents a work on the influence of pier settlement on structural stress of longitudinal connected track in high-speed railways. Primarily, the generation mechanism of additional structural stress of LCT caused by pier settlement is explained. On this basis, the deformation of LCT caused by pier settlement is analytically deduced and a dynamic model of high-speed train-LCT-bridge coupled system considering pier settlement is established, adopting which the additional structural stresses of LCT are discussed from static and dynamic perspective. Finally, some interesting conclusions are reached in Section 7.

\section{Generation Mechanism of Additional Structural Stress of LCT Caused by Pier Settlement}

LCT consists of several components, as shown in Figure 1. It should be noted that the concrete base is not fixed with the bridge. The base and deck can separate from each other under foundation deformation because of the sliding layer, whose elasticity is very weak.

Pier settlement directly causes vertical deformation of track-bridge system, as seen in Figure 1. When pier settlement occurs, the bridge moves downwards. Further the track structure bends in vertical direction due to the selfweight. Because of the longitudinally connected characteristic of the slab and base, gaps appear between the base and the bridge beams, and additional stresses obviously occur in the concrete structures.

Moreover, settlement appears below the \#2 pier in Figure 1, while the bottoms of the \#1 and \#3 piers are fixed. Due to the longitudinal connected characteristic, gaps mainly appear at the following locations, as well as the additional structural stresses:

(a) The location above the settlement pier (\#2 pier)

(b) The locations above the adjacent piers (\#1 and \#3 piers)

The bending deformation of LCT results in static additional structural stresses. When trains are running through, the dynamic structural stresses are aroused, which greatly affect the stability of LCT because concrete structures cannot withstand larger tensile forces and may even damage LCT and threaten the running safety of operating trains.

\section{Static Model of LCT-Bridge System considering Pier Settlement}

The influences of pier settlement on LCT are investigated from static and dynamic perspectives. On this basis, the static model of the LCT-bridge system considering pier settlement is established in this section, while the dynamic model of the train-LCT-bridge system is described in the next section.

The rail is considered as free beam, as seen in Figure 2, where $F_{\mathrm{r}, i}$ is fastener force and $G_{\mathrm{r}}$ is self-weight.

Adopting the method of solving free beam in [10], the rail deformation $z_{\mathrm{r}}$ at fastener location can be given as

$$
\left\{\begin{array}{l}
z_{\mathrm{r}, 1}=\frac{\left(\sum_{n=1}^{2 M N} G_{\mathrm{r}}-\sum_{n=2}^{2 M N-1} F_{\mathrm{r}, n}\right)}{\left(2 k_{\mathrm{p}}\right)} \\
z_{\mathrm{r}, i}=\sum_{j=1}^{i} \frac{\left(G_{\mathrm{r}}-F_{\mathrm{r}, j}\right)\left(l_{\mathrm{r}}-x_{\mathrm{r}, j}\right)}{6 E_{\mathrm{r}} I_{\mathrm{r}} l_{\mathrm{r}}}\left[\frac{l_{\mathrm{r}}}{l_{\mathrm{r}}-x_{\mathrm{r}, j}}\left(x_{\mathrm{r}, i}-x_{\mathrm{r}, j}\right)^{3}-\left(2 l_{\mathrm{r}} x_{\mathrm{r}, j}-x_{\mathrm{r}, j}^{2}\right) x_{\mathrm{r}, i}-x_{\mathrm{r}, i}^{3}\right] \\
+\sum_{j=i+1}^{2 M N} \frac{\left(G_{\mathrm{r}}-F_{1, j}\right)\left(l_{\mathrm{r}}-x_{\mathrm{r}, j}\right) x_{r, i}}{6 E_{\mathrm{r}} I_{\mathrm{r}} l_{\mathrm{r}}}\left(2 l_{\mathrm{r}} x_{\mathrm{r}, j}-x_{\mathrm{r}, j}^{2}-x_{\mathrm{r}, i}^{2}\right)+z_{\mathrm{r}, 1}, \quad i=2 \sim 2 M N-1, \\
z_{\mathrm{r}, 2 M N}=\frac{\left(\sum_{n=1}^{2 M N} G_{\mathrm{r}}-\sum_{n=2}^{2 M N-1} F_{\mathrm{r}, n}\right)}{\left(2 k_{\mathrm{p}}\right)},
\end{array}\right.
$$

where $x_{\mathrm{r}, j}$ is the coordinate of the $j$ th fastener, $M$ is half the number of bridges, $N$ is the number of fasteners on one bridge, $k_{\mathrm{p}}$ is stiffness of fastener, $E_{\mathrm{r}}$ is the elasticity modulus of rail, $I_{\mathrm{r}}$ is inertia of the cross section of rail, and $l_{\mathrm{r}}$ is the calculated length of rail.

Furthermore, the abovementioned expression can be given in the matrix form:

$$
\mathbf{Z}_{\mathrm{r}}=\mathbf{A} \cdot \mathbf{G}_{\mathrm{r}}-\mathbf{B} \cdot \mathbf{F}_{\mathrm{r}}
$$

where $\boldsymbol{Z}_{\mathbf{r}}$ is matrix of rail deformation at fastener location, $\boldsymbol{F}_{\mathbf{r}}$ is matrix of fastener force, $\boldsymbol{G}_{\mathbf{r}}$ is matrix of self-weight effect, and $\boldsymbol{A}$ and $\boldsymbol{B}$ are relationship matrices.

Similarly, the deformations of slab and base can be written as 


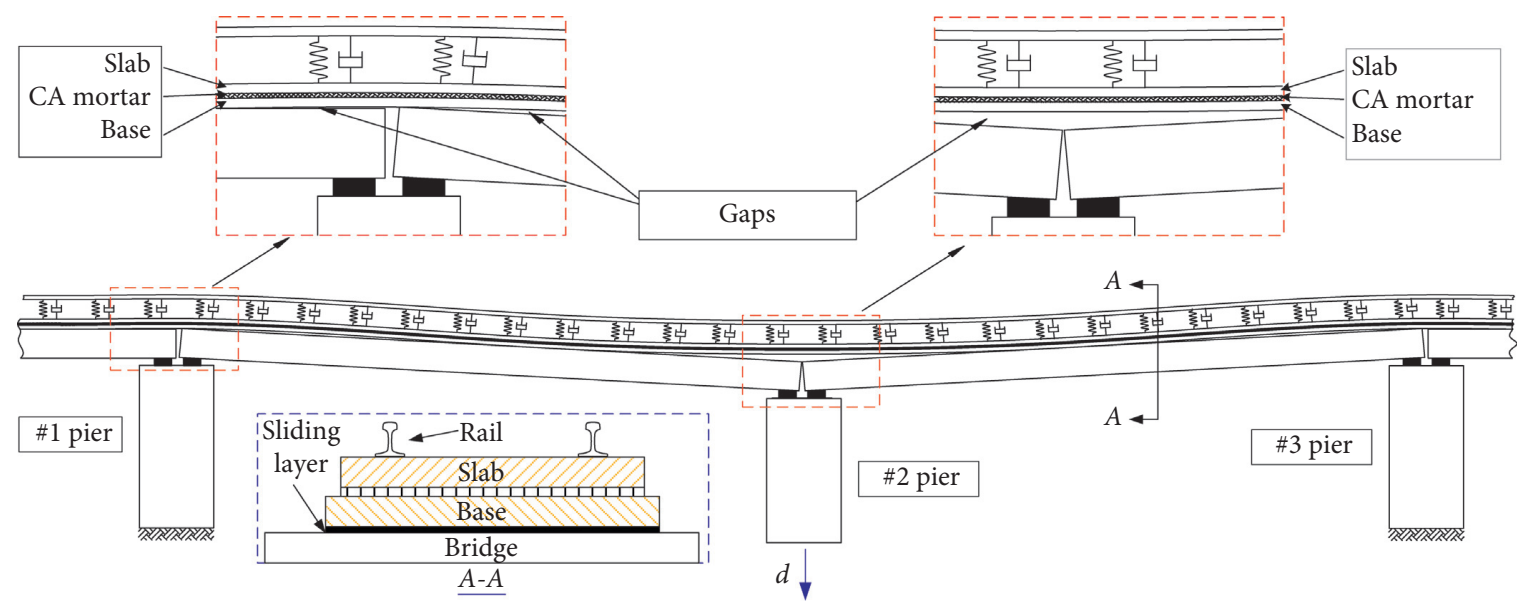

FIGURE 1: Deformation of LCT caused by pier settlement.

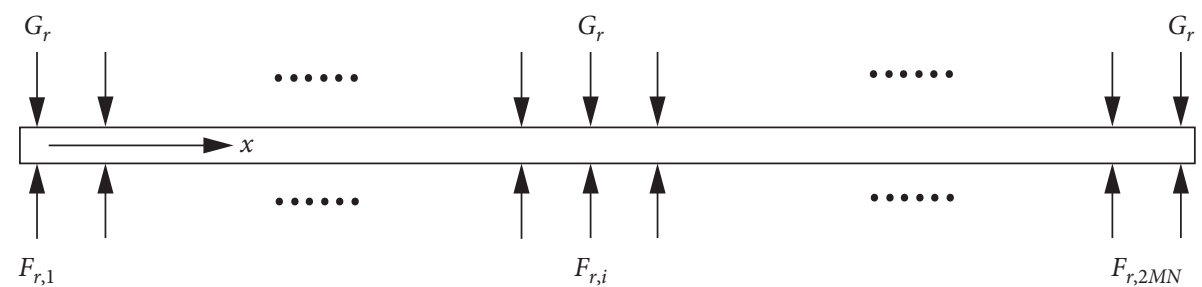

FIgURE 2: Forces applied on rail.

$$
\begin{aligned}
& \left\{\begin{array}{l}
z_{\mathrm{s}, 1}=\frac{\left(\sum_{n=1}^{2 M N}\left(G_{\mathrm{s}}+F_{\mathrm{r}, n}\right)-\sum_{n=2}^{2 M N-1} F_{\mathrm{s}, n}\right)}{\left(2 k_{\mathrm{s}}\right)}, \\
z_{\mathrm{s}, i}=\sum_{j=1}^{i} \frac{\left(G_{\mathrm{s}}+F_{\mathrm{r}, j}-F_{\mathrm{s}, j}\right)\left(l_{\mathrm{s}}-x_{\mathrm{s}, j}\right)}{6 E_{\mathrm{s}} I_{\mathrm{s}} l_{\mathrm{s}}}\left[\frac{l_{\mathrm{s}}}{l_{\mathrm{s}}-x_{\mathrm{s}, j}}\left(x_{\mathrm{s}, i}-x_{\mathrm{s}, j}\right)^{3}-\left(2 l_{\mathrm{s}} x_{\mathrm{s}, j}-x_{\mathrm{s}, j}^{2}\right) x_{\mathrm{s}, i}-x_{\mathrm{s}, j}^{3}\right] \\
+\sum_{j=i+1}^{2 M N} \frac{\left(G_{\mathrm{s}}+F_{\mathrm{r}, j}-F_{\mathrm{s}, j}\right)\left(l_{\mathrm{s}}-x_{\mathrm{s}, j}\right) x_{s, i}}{6 E_{\mathrm{s}} I_{\mathrm{s}} l_{\mathrm{s}}}\left(2 l_{\mathrm{s}} x_{\mathrm{s}, j}-x_{\mathrm{s}, j}^{2}-x_{\mathrm{s}, j}^{2}\right)+z_{\mathrm{s}, 1}, \quad i=2 \sim 2 M N-1,
\end{array}\right. \\
& z_{\mathrm{s}, 2 M N}=\frac{\left(\sum_{n=1}^{2 M N}\left(G_{\mathrm{s}}+F_{\mathrm{r}, n}\right)-\sum_{n=2}^{2 M N-1} F_{\mathrm{s}, n}\right)}{\left(2 k_{\mathrm{s}}\right)} \\
& \left\{\begin{array}{l}
z_{\mathrm{p}, 1}=z_{\mathrm{p}, 2 M N}=\frac{\left(\sum_{n=1}^{2 M N}\left(G_{\mathrm{p}}+F_{\mathrm{s}, n}\right)-\sum_{n=2}^{2 M N-1} F_{\mathrm{p}, n}\right)}{\left(2 k_{\mathrm{b}}\right)}, \\
z_{\mathrm{p}, i}=\sum_{j=1}^{i} \frac{\left(G_{\mathrm{p}}+F_{\mathrm{s}, j}-F_{\mathrm{p}, j}\right)\left(l_{\mathrm{p}}-x_{\mathrm{p}, j}\right)}{6 E_{p} I_{p} l_{p}}\left[\frac{l_{\mathrm{p}}}{l_{\mathrm{p}}-x_{\mathrm{p}, j}}\left(x_{\mathrm{p}, i}-x_{\mathrm{p}, j}\right)^{3}-\left(2 l_{\mathrm{p}} x_{\mathrm{p}, j}-x_{\mathrm{p}, j}^{2}\right) x_{\mathrm{p}, i}-x_{\mathrm{p}, i}^{3}\right]
\end{array}\right. \\
& +\sum_{j=i+1}^{2 M N} \frac{\left(G_{\mathrm{p}}+F_{\mathrm{s}, j}-F_{\mathrm{p}, j}\right)\left(l_{\mathrm{p}}-x_{\mathrm{p}, j}\right) x_{\mathrm{p}, i}}{6 E_{\mathrm{p}} I_{\mathrm{p}} l_{\mathrm{p}}}\left(2 l_{\mathrm{p}} x_{\mathrm{p}, j}-x_{\mathrm{p}, j}^{2}-x_{\mathrm{p}, i}^{2}\right)+z_{\mathrm{p}, 1}, \quad i=2 \sim 2 M N-1, \\
& z_{\mathrm{p}, 1}=z_{\mathrm{p}, 2 M N}=\frac{\left(\sum_{n=1}^{2 M N}\left(G_{\mathrm{p}}+F_{\mathrm{s}, n}\right)-\sum_{n=2}^{2 M N-1} F_{\mathrm{p}, n}\right)}{\left(2 k_{\mathrm{b}}\right)}
\end{aligned}
$$


where $z_{\mathrm{s}}$ and $z_{\mathrm{p}}$ are deformations of slab and base at fastener locations, $k_{\mathrm{s}}$ is stiffness of filler layer, and $k_{\mathrm{b}}$ is stiffness of contact spring between the base and deck.

Hence, the matrices of deformations of slab and base are given by

$$
\left\{\begin{array}{l}
\mathbf{Z}_{\mathrm{s}}=\mathbf{C} \cdot\left(\mathbf{G}_{\mathrm{s}}+\mathbf{F}_{\mathrm{r}}\right)-\mathbf{D} \cdot \mathbf{F}_{\mathrm{s}}, \\
\mathbf{Z}_{\mathrm{p}}=\mathbf{G} \cdot\left(\mathbf{G}_{\mathrm{p}}+\mathbf{F}_{\mathrm{s}}\right)-\mathbf{H} \cdot \mathbf{F}_{\mathrm{p}},
\end{array}\right.
$$

where $\boldsymbol{C}, \boldsymbol{D}, \boldsymbol{G}$, and $\boldsymbol{H}$ are relationship matrices.

The $M$ th bridge deformation subject to pier settlement is shown in Figure 3 , where $d$ is settlement value, $x_{\mathrm{b}}^{M}$ is the coordinate on the beam, $l_{\mathrm{b} 0}$ is the distance between beamend and bearing location, and $l_{\mathrm{b} 1}$ is the distance between two bearings.

The deformation of bridge $z_{\mathrm{b}}$ can be written as

$$
z_{\mathrm{b}}\left(x_{\mathrm{b}}^{M}\right)=\frac{\left(x_{\mathrm{b}}^{M}-l_{\mathrm{b} 1}\right) \cdot d}{l_{\mathrm{b} 0}} .
$$

Thus, the bridge deformation can also be described in the following matrix form, where $\boldsymbol{L}$ is the relationship matrix:

$$
\mathbf{Z}_{\mathrm{b}}=\mathbf{L} \cdot d \text {. }
$$

Furthermore, the interlayer forces can be given by

$$
\left\{\begin{array}{l}
\mathbf{F}_{\mathrm{r}}=k_{\mathrm{p}}\left(\mathbf{Z}_{\mathrm{r}}-\mathbf{Z}_{\mathrm{s}}\right), \\
\mathbf{F}_{\mathrm{s}}=k_{\mathrm{s}}\left(\mathbf{Z}_{\mathrm{s}}-\mathbf{Z}_{\mathrm{p}}\right), \\
\mathbf{F}_{\mathrm{p}}=\mathbf{K}_{\mathrm{b}}\left(\mathbf{Z}_{\mathrm{p}}-\mathbf{Z}_{\mathrm{b}}\right),
\end{array}\right.
$$

where $K_{\mathbf{b}}$ is stiffness matrix of contact spring between base and deck, whose element is $k_{\mathrm{b} i}$, which is expressed as

$$
k_{\mathrm{b} i}= \begin{cases}0, & (\text { seperated section), } \\ k_{\mathrm{b}}, & \text { (contacted section) }\end{cases}
$$

On this basis, the deformations and interlayer forces of LCT system can be finally given by

$$
\begin{aligned}
& \left(\begin{array}{ccc}
\mathbf{E}+k_{\mathrm{r}} \cdot \mathbf{B} & -k_{\mathrm{r}} \cdot \mathbf{B} & 0 \\
-k_{\mathrm{r}} \cdot \mathbf{C} & \mathbf{E}+k_{\mathrm{r}} \cdot \mathbf{C}+k_{\mathrm{s}} \cdot \mathbf{D} & -k_{\mathrm{s}} \cdot \mathbf{D} \\
0 & -k_{\mathrm{s}} \cdot \mathbf{G} & \mathbf{E}+k_{\mathrm{s}} \cdot \mathbf{G}+\mathbf{H} \cdot \mathbf{K}_{\mathrm{b}}
\end{array}\right) \\
& \left(\begin{array}{c}
\mathbf{Z}_{\mathrm{r}} \\
\mathbf{Z}_{\mathrm{s}} \\
\mathbf{Z}_{\mathrm{p}}
\end{array}\right)=\left(\begin{array}{c}
\mathbf{A} \cdot \mathbf{G}_{\mathrm{r}} \\
\mathbf{C} \cdot \mathbf{G}_{\mathrm{s}} \\
\mathbf{G} \cdot \mathbf{G}_{\mathrm{p}}+\mathbf{H} \cdot \mathbf{K}_{\mathrm{b}} \cdot \mathbf{L} \cdot d
\end{array}\right) .
\end{aligned}
$$

Adopting (9), the deformations of the rail, the slab, and the base can be calculated, as well as the fastener forces, the filler layer forces, and the contact forces.

\section{Dynamic Model of High-Speed Train-LCT- Bridge System considering Pier Settlement}

The dynamic model of high-speed train-LCT-bridge system considering pier settlement is described in this section, as shown in Figure 4. The train, the track, and the bridge are regarded as an integrated dynamic system, in which the train and the track are coupled by the wheel-rail interactive relationship, and the track and the bridge are linked through the track-bridge interaction.

4.1. Train Model. The train consists of a series of vehicles. Each vehicle is modelled as a mass-spring-damper system consisting of a car body, two bogie frames, four wheelsets, and two-stage suspensions. Each vehicle has 10 DOFs, including the vertical and pitch motions of the car body and two bogie frames, and the vertical motion of each wheelset. The dynamic equations for all the seven bodies are given as follows.

Vertical motion of the car body:

$$
M_{c} \ddot{Z}_{c}+2 C_{s z} \dot{Z}_{c}+2 K_{s z} Z_{c}-C_{s z} \dot{Z}_{t 1}-K_{s z} Z_{t 1}-C_{s z} \dot{Z}_{t 2}-K_{s z} Z_{t 2}=M_{c} g .
$$

Pitch motion of the car body:

$$
J_{c} \ddot{\beta}_{c}+2 C_{s z} l_{c}^{2} \dot{\beta}_{c}+2 K_{s z} l_{c}^{2} Z_{c}+C_{s z} l_{c} \dot{Z}_{t 1}+K_{s z} l_{c} Z_{t 1}-C_{s z} l_{c} \dot{Z}_{t 2}-K_{s z} l_{c} Z_{t 2}=0
$$

Vertical motion of the front frame:

$$
M_{t} \ddot{Z}_{t 1}+\left(2 C_{p z}+C_{s z}\right) \dot{Z}_{t 1}+\left(2 K_{p z}+K_{s z}\right) Z_{t 1}-C_{s z} \dot{Z}_{c}-K_{s z} Z_{c}-C_{p z} \dot{Z}_{w 1}-C_{p z} \dot{Z}_{w 2}-K_{p z} Z_{w 1}-K_{p z} Z_{w 2}+C_{s z} l_{c} \dot{\beta}_{c}+K_{s z} l_{c} \beta_{c}=M_{t} g
$$




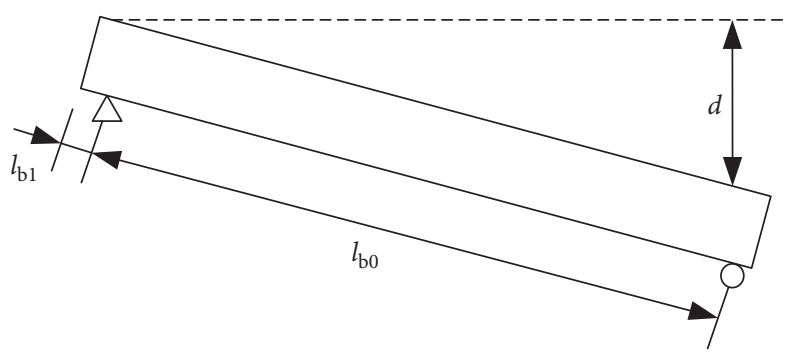

Figure 3: Bridge deformation.

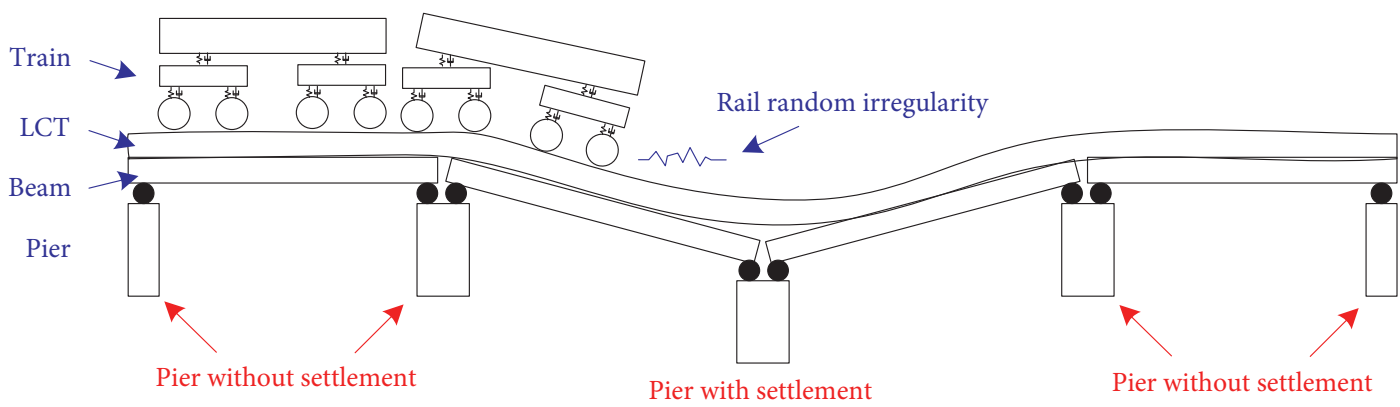

FIGURE 4: Dynamic model of the high-speed train-LCT-bridge system.

Pitch motion of the front frame:

$$
J_{t} \ddot{\beta}_{t 1}+2 C_{p z} l_{t}^{2} \dot{\beta}_{t 1}+2 K_{p z} l_{t}^{2} \beta_{t 1}+C_{p z} l_{t} \dot{Z}_{w 1}+K_{p z} l_{t} Z_{w 1}-C_{p z} l_{t} \dot{z}_{w 2}-K_{p z} l_{t} Z_{w 2}=0
$$

Vertical motion of the rear frame:

Pitch motion of the rear frame:

$$
\begin{aligned}
& M_{t} \ddot{Z}_{t 2}+\left(2 C_{p z}+C_{s z}\right) \dot{Z}_{t 2}+\left(2 K_{p z}+K_{s z}\right) Z_{t 2}-C_{s z} \dot{Z}_{c} \\
& \quad-K_{s z} Z_{c}-C_{p z} \dot{Z}_{w 3}-C_{p z} \dot{Z}_{w 4}-K_{p z} Z_{w 3}-K_{p z} Z_{w 4} \\
& +C_{s z} l_{c} \dot{\beta}_{c}+K_{s z} l_{c} \beta_{c}=M_{t} g .
\end{aligned}
$$

$$
J_{t} \ddot{\beta}_{t 2}+2 C_{p z} l_{t}^{2} \dot{\beta}_{t 2}+2 K_{p z} l_{t}^{2} \beta_{t 2}+C_{p z} l_{t} \dot{Z}_{w 3}+K_{p z} l_{t} Z_{w 3}-C_{p z} l_{t} \dot{Z}_{w 4}-K_{p z} l_{t} Z_{w 4}=0
$$

Vertical motion of 1st wheelset:

$$
M_{w} \ddot{Z}_{w 1}+C_{p z} \dot{Z}_{w 1}+K_{p z} Z_{w 1}-C_{p z} \dot{Z}_{t 1}-K_{p z} Z_{t 1}+C_{p z} l_{t} \dot{\beta}_{t 1}+K_{p z} l_{t} \beta_{t 1}+2 p_{1}(t)-M_{w} g=F_{01}(t) .
$$

Vertical motion of 2nd wheelset:

$$
M_{w} \ddot{Z}_{w 2}+C_{p z} \dot{Z}_{w 2}+K_{p z} Z_{w 2}-C_{p z} \dot{Z}_{t 1}-K_{p z} Z_{t 1}-C_{p z} l_{t} \dot{\beta}_{t 1}-K_{p z} l_{t} \beta_{t 1}+2 p_{2}(t)-M_{w} g=F_{02}(t) .
$$


Vertical motion of 3rd wheelset:

$$
M_{w} \ddot{Z}_{w 3}+C_{p z} \dot{Z}_{w 3}+K_{p z} Z_{w 3}-C_{p z} \dot{Z}_{t 2}-K_{p z} Z_{t 2}+C_{p z} l_{t} \dot{\beta}_{t 2}+K_{p z} l_{t} \beta_{t 2}+2 p_{3}(t)-M_{w} g=F_{03}(t)
$$

Vertical motion of 4 th wheelset:

$$
M_{w} \ddot{Z}_{w 4}+C_{p z} \dot{Z}_{w 4}+K_{p z} Z_{w 4}-C_{p z} \dot{Z}_{t 2}-K_{p z} Z_{t 2}-C_{p z} l_{t} \dot{\beta}_{t 2}-K_{p z} l_{t} \beta_{t 2}+2 p_{4}(t)-M_{w} g=F_{04}(t)
$$

where $Z$ and $\beta$ are the vertical displacement and pitch angle; $M$, $C$, and $K$ represent mass, damping, and stiffness of each body, respectively; $J$ is the moment of inertia; subscripts " $c$," " $t$," and " $w$ " denote car body, frame, and wheelset, respectively; $C_{\mathrm{p} z}$ and $C_{\mathrm{s} z}$ are the damping of the primary suspension and the secondary suspension; $K_{\mathrm{p} z}$ and $K_{\mathrm{s} z}$ are the stiffness of the primary suspension and the secondary suspension. $l_{\mathrm{t}}$ is the wheelbase, and $l_{\mathrm{c}}$ is the length between bogie centers.

4.2. LCT Model. LCT consists of several parts, namely, rail, fastener, slab, CA mortar, base, and sliding layer, as seen in Figure 1. It should be noted that, as a plane model, the left and right rails are combined into one beam, and the applied wheel-rail forces are the superposition of the left wheel-rail force and the right wheel-rail force.

The vibration equation of rail is written as

$$
\begin{aligned}
E_{\mathrm{r}} I_{\mathrm{r}} \frac{\partial^{4} Z_{\mathrm{r}}(x, t)}{\partial x^{4}}+m_{\mathrm{r}} \frac{\partial^{2} Z_{\mathrm{r}}(x, t)}{\partial t^{2}}= & -\sum_{i=1}^{N_{\mathrm{f}}} F_{\mathrm{f} i}(t) \delta\left(x-x_{i}\right) \\
& +\sum_{j=1}^{4} p_{j} \delta\left(x-x_{\mathrm{w} j}\right),
\end{aligned}
$$

in which

$$
F_{\mathrm{f} i}(t)=k_{\mathrm{f}}\left[Z_{\mathrm{r}}\left(x_{i}, t\right)-Z_{\mathrm{s}}\left(x_{i}, t\right)\right]+c_{\mathrm{f}}\left[\dot{Z}_{\mathrm{r}}\left(x_{i}, t\right)-\dot{Z}_{\mathrm{s}}\left(x_{i}, t\right)\right] \text {, }
$$

where $E_{\mathrm{r}} I_{\mathrm{r}}$ is the stiffness of the rail; $Z_{\mathrm{r}}(x, t)$ is the dynamic rail displacement; $Z_{\mathrm{s}}(x, t)$ is the slab displacement; $F_{\mathrm{f} i}$ is the $i$ th fastener force; $N_{\mathrm{f}}$ is the number of fasteners; $p_{j}$ is the $j$ th wheel-rail force; $x_{i}$ is the location of the $i$ th fastener; $x_{w j}$ is the location of the $j$ th wheelset; $k_{\mathrm{f}}$ and $c_{\mathrm{f}}$ are the stiffness and damping of each group of fasteners.

The vibration mode function of simply supported beam is given as

$$
Z_{k}(x)=\sqrt{\frac{2}{m_{\mathrm{r}} l}} \sin \frac{k \pi x}{l},
$$

where $m_{\mathrm{r}}$ is the mass of rail per unit length and $l$ is the calculated length of rail.

Thus, the solution for (20) is

$$
Z_{\mathrm{r}}(x, t)=\sum_{k=1}^{N M} Z_{k}(x) q_{k}(t),
$$

where $q_{k}(t)$ is the generalized coordinate and $N M$ is the number of mode shapes.

Hence, (20) can be finally written as

$$
\begin{aligned}
& \ddot{q}_{k}(t)+\sum_{i=1}^{N} c_{\mathrm{f}} Z_{k}\left(x_{i}\right) \sum_{h=1}^{N M} Z_{h}\left(x_{i}\right) \dot{q}_{h}(t)+\frac{E_{\mathrm{r}} I_{\mathrm{r}}}{m_{r}}\left(\frac{k \pi}{l}\right)^{4} q_{k}(t) \\
& +\sum_{i=1}^{N} k_{\mathrm{f}} Z_{k}\left(x_{i}\right) \sum_{h=1}^{N M} Z_{h}\left(x_{i}\right) q_{h}(t)-\sum_{i=1}^{N} c_{\mathrm{f}} Z_{k}\left(x_{i}\right) \dot{Z}_{\mathrm{s}}\left(x_{i}, t\right) \\
& -\sum_{i=1}^{N} k_{\mathrm{f}} Z_{k}\left(x_{i}\right) Z_{\mathrm{s}}\left(x_{i}, t\right)=\sum_{j=1}^{4} p_{j}(t) Z_{k}\left(x_{\mathrm{w} j}\right), \quad k=1 \sim N M .
\end{aligned}
$$

Employing the modelling method of rail from static and dynamic perspectives, the mechanical equations of concrete slab and base can also be deduced, which are not described repeatedly in this present work.

Moreover, the interaction forces between different layers are expressed by

$$
\left\{\begin{array}{l}
F_{\mathrm{f} i}=k_{\mathrm{f}}\left[Z_{\mathrm{r}}\left(x_{i}\right)-Z_{\mathrm{s}}\left(x_{i}\right)\right], \\
F_{\mathrm{s} i}=k_{\mathrm{s}}\left[\left[Z_{\mathrm{s}}\left(x_{i}\right)-Z_{\mathrm{p}}\left(x_{i}\right)\right],\right. \\
F_{\mathrm{p} i}=k_{\mathrm{p}}\left[Z_{\mathrm{p}}\left(x_{i}\right)-Z_{\mathrm{b}}\left(x_{i}\right)\right],
\end{array}\right.
$$

where $F_{\mathrm{f}}, F_{\mathrm{s}}$, and $F_{\mathrm{p}}$ are fastener force, force of CA mortar spring, and contact force between the track and bridge, respectively; $k_{\mathrm{f}}, k_{\mathrm{s}}$, and $k_{\mathrm{p}}$ are the stiffness of fastener, the stiffness of mortar spring, and the stiffness of contact force between track and bridge, respectively. $Z_{\mathrm{r}}, Z_{\mathrm{s}}, Z_{\mathrm{p}}$, and $Z_{\mathrm{b}}$ are displacements of rail, slab, base, and bridge, respectively.

Furthermore, the dynamic moments of slab and base can be expressed by [14]

$$
\left\{\begin{array}{l}
M_{\mathrm{s}}=E_{\mathrm{s}} I_{\mathrm{s}} \frac{\partial^{2} Z_{\mathrm{s}}(x, t)}{\partial x^{2}} \\
M_{\mathrm{p}}=E_{\mathrm{p}} I_{\mathrm{p}} \frac{\partial^{2} Z_{\mathrm{p}}(x, t)}{\partial x^{2}}
\end{array}\right.
$$

where $M_{\mathrm{s}}$ and $M_{\mathrm{p}}$ are dynamic moments of slab and base. 
Hence, the dynamic stresses of slab and base are calculated by

$$
\left\{\begin{array}{l}
\sigma_{\mathrm{s}}=\frac{M_{\mathrm{s}}}{W_{\mathrm{s}}}, \\
\sigma_{\mathrm{p}}=\frac{M_{\mathrm{p}}}{W_{\mathrm{p}}} .
\end{array}\right.
$$

4.3. Bridge Model. Bridge is modelled by the finite element method in this work $[15,16]$, the dynamic equation of which can be integrated as

$$
\mathbf{M}_{\mathrm{b}} \ddot{x}_{\mathrm{b}}+\mathrm{C}_{\mathrm{b}} \dot{x}_{\mathrm{b}}+\mathrm{K}_{\mathrm{b}} x_{\mathrm{b}}=\mathrm{F}_{\mathrm{b}},
$$

where $\boldsymbol{M}_{\mathrm{b}} / \boldsymbol{C}_{\mathrm{b}} / \boldsymbol{K}_{\mathrm{b}}$ are mass/damping/stiffness matrices of bridge and $\boldsymbol{F}_{\mathbf{b}}$ is the load vector acting on bridge.

4.4. Wheel-Rail Interaction. The wheel-rail interface connects the vehicle and track subsystems as described by the Hertz nonlinear elastic theory. Therefore, the wheel-rail force is determined by [17-19]

$$
p(t)=\left[\frac{1}{G} \delta Z(t)\right]^{3 / 2},
$$

where $G$ is the contact constant of wheel and rail and $\delta Z(t)$ is the elastic compression deformation, which is written as

$$
\delta Z(t)=Z_{\mathrm{w}}(t)-Z_{\mathrm{r}}(t)-Z_{0}(t),
$$

where $Z_{\mathrm{w}}(t), Z_{\mathrm{r}}(t)$, and $Z_{0}(t)$ represent the wheel displacement, the rail displacement, and the rail random irregularity at the same position, respectively.

4.5. Rail Random Irregularity. In order to calculate the dynamic responses of train running on China's high-speed railways more accurately, the average spectrum of China's high-speed railway ballastless track irregularity is adopted as the rail random irregularity, which is expressed as

$$
S(f)=\frac{A}{f^{n}},
$$

where the unit of $S(f)$ is $\mathrm{mm}^{2} /(1 / \mathrm{m})$; $f$ is spatial frequency (1/ $\mathrm{m})$; and $A$ and $n$ are fitting coefficients.

\section{Investigation of Additional Structural Stress of LCT from Static Perspective}

According to the mechanics of materials, the maximum structural stresses of slab and base appear on the top surfaces and bottom surfaces because the cross sections of track components are rectangular. Hence, in the following calculations, the additional structural stresses of slab and base on top/bottom surfaces are emphasized. The parameters of LCT are given in Table 1.

The influence of pier settlement on the additional structural stress of LCT from static perspective is described in this section. Figure 5 displays the stresses on the top and
TABLE 1: Parameters of LCT.

\begin{tabular}{lcc}
\hline Item & Value & Unit \\
\hline Fastener spacing & 0.65 & $\mathrm{~m}$ \\
Stiffness of the fastener (static/dynamic) & $30 / 60$ & $\mathrm{MN} / \mathrm{m}$ \\
Damping of the fastener & 30 & $\mathrm{kN} \cdot \mathrm{s} / \mathrm{m}$ \\
Cross section of the slab & $2.55 \times 0.2$ & $\mathrm{~m}$ \\
Elasticity modulus of the slab & $3.6 \times 10^{4}$ & $\mathrm{MPa}$ \\
Cross section of the CA mortar & $2.55 \times 0.03$ & $\mathrm{~m}$ \\
Elasticity modulus of the CA mortar & 7500 & $\mathrm{MPa}$ \\
Cross section of the base & $2.95 \times 0.19$ & $\mathrm{~m}$ \\
Elasticity modulus of the base & $3.3 \times 10^{4}$ & $\mathrm{MPa}$ \\
\hline
\end{tabular}

bottom surfaces of slab and base subject to the pier settlement of $3 \mathrm{~mm}$.

As seen from Figure 5, the slab and base obviously deform in vertical direction subject to pier settlement. The additional structural stress on the top surface of slab is the largest, which is about $600 \mathrm{kPa}$, while the stress on the top surface of base is the smallest, which is about $200 \mathrm{kPa}$. As for concrete slab, the additional stress on top surface is larger than that on bottom surface, while on the contrary, the additional stress on top surface is smaller than that on bottom surface for the concrete base.

Moreover, the results clearly present three peaks in each figure, that is, the settlement pier location and the adjacent pier locations. Though the deformation of LCT at the settlement pier location is much larger than the upward movement at the adjacent pier locations, the structural stresses at these locations are almost the same. As for the stress on the bottom surface of base, the additional stresses at adjacent pier locations are even larger than those at settlement pier location.

On the top surfaces of slab and base, tensile stresses appear at the adjacent pier locations and compressive stresses appear at settlement pier location. On the contrary, tensile stresses appear at the settlement pier location and compressive stresses appear at the adjacent pier locations. Because concrete structures cannot withstand larger tensile forces, the following analyses mainly focus on the additional tensile stresses of LCT.

Further, the spatial distribution of additional stress on the top surface of slab is illustrated in Figure 6. As seen from the result, structural stresses on the top surface of slab appear at three pier locations, including the settlement pier location and the adjacent pier locations. Another interesting phenomenon is that the additional stress changes slightly along the lateral direction, as well as the stresses on the bottom surface of slab and on the top/bottom surfaces of base.

Subject to different pier settlement values, the additional tensile stresses at different locations are displayed in Figure 7. As seen from the results, additional tensile stresses at different locations increase with the increment of pier settlement value. The stress on top surface of slab is the largest. With the settlement changes from $1 \mathrm{~mm}$ to $5 \mathrm{~mm}$, the tensile stress on the top surface of slab changes from $318.1 \mathrm{kPa}$ to $854.4 \mathrm{kPa}$, the growth rate of which reaches $169 \%$, while the growth rate of tensile stress on the bottom surface of base even reaches $288 \%$. This indicates that the pier settlement indeed greatly affects the stability of LCT. 


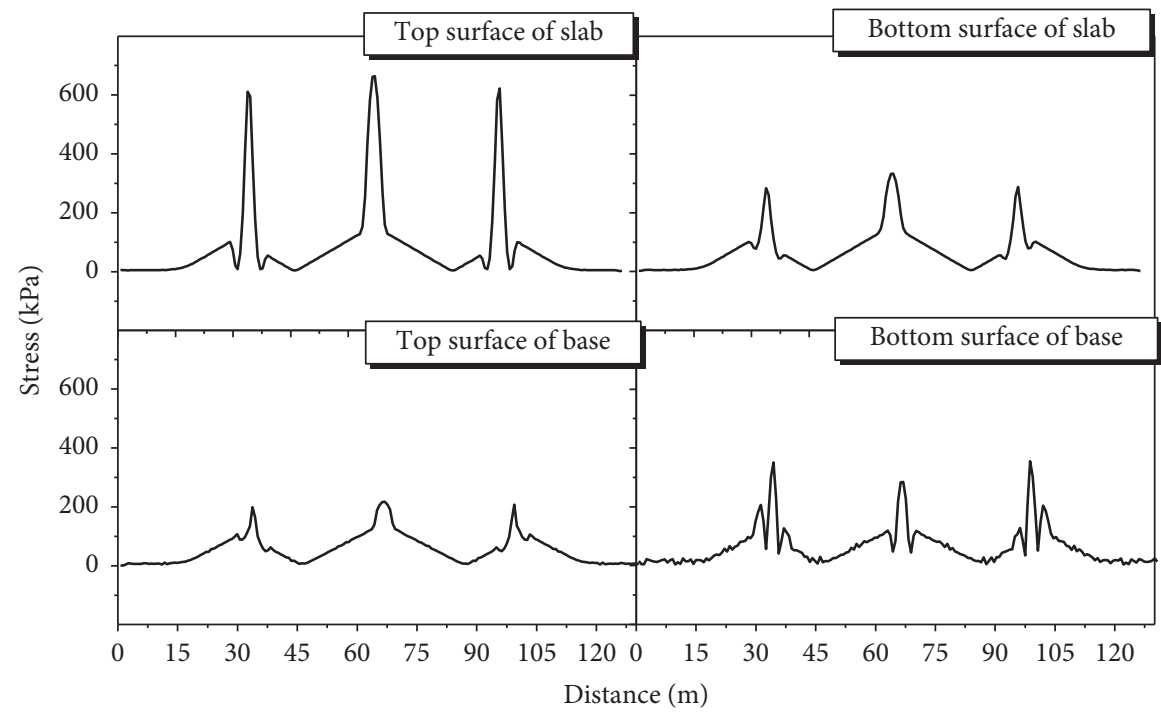

FIGURE 5: Static stresses on the top and bottom surfaces of the slab and base.

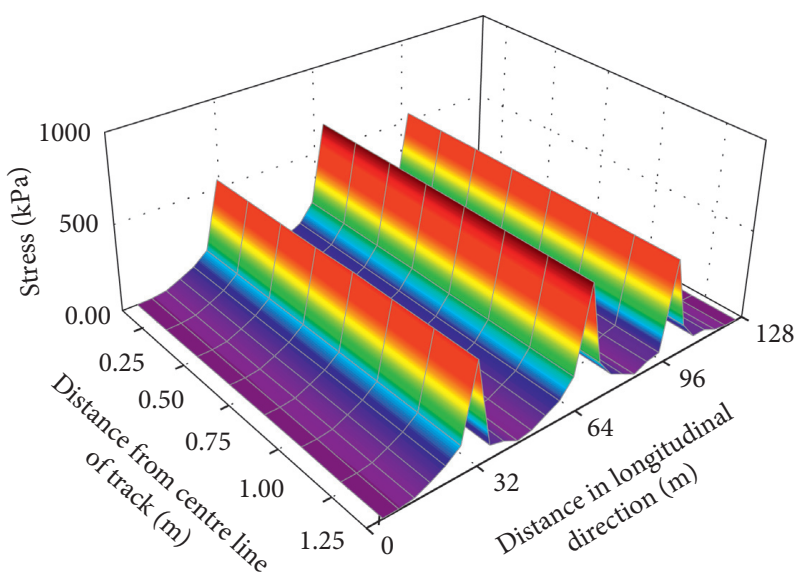

FIgURE 6: Spatial distribution of static additional stress on the top surface of slab.

According to "Code for Design of Concrete Structures (GB50010-2010)," the tensile strengths of concrete slab and base are $1.96 \mathrm{MPa}$ and $1.71 \mathrm{MPa}$, respectively. The calculated tensile stresses of slab and base with settlement of $5 \mathrm{~mm}$ are $0.85 \mathrm{MPa}$ and $0.57 \mathrm{MPa}$, respectively, indicating that the safe margins of concrete slab and base are enough subject to pier settlement.

However, according to the tested data on Beijing-Tianjin high-speed railway, the uneven pier settlement difference between adjacent two piers reaches $20 \mathrm{~mm}$ [14], which has exceeded the limit value in relevant codes. To determine the stability of LCT with larger settlement values, a further evaluation is performed.

Fitting expressions of maximum tensile stresses of slab and base are calculated according to Figure 6, as written by

$$
\begin{cases}\sigma_{\text {slab }}=134.13 d+202.79, & R^{2}=0.9933, \\ \sigma_{\text {base }}=90.013 d+16.907, & R^{2}=0.9928,\end{cases}
$$

where $\sigma_{\text {slab }}$ and $\sigma_{\text {base }}$ are tensile stresses on the top surface of slab and on the bottom surface of base (unit: $\mathrm{kPa}$ ); $d$ is the settlement value. As seen from the expressions, the fitting coefficients are both larger than 0.99, indicating that the tensile stress and the pier settlement have a good linear relationship.

With the increase of pier settlement, the tensile stresses of base and slab also increase. When the stresses exceed the tensile strengths of concrete slab and base (1.96 MPa and $1.71 \mathrm{MPa}$ ), the critical pier settlement values are calculated to be $13.1 \mathrm{~mm}$ and $18.8 \mathrm{~mm}$ employing equation (18). Hence, the pier settlement should be less than $13.1 \mathrm{~mm}$ to ensure the stability of LCT from the static perspective.

\section{Investigation of Additional Structural Stress of LCT from Dynamic Perspective}

The dynamic additional tensile stress of LCT subject to pier settlement and running train is investigated in this part. In the calculations, the parameters of train can be found in Table 2, and the running speeds are set to $250 \mathrm{~km} / \mathrm{h}, 300 \mathrm{~km} /$ $\mathrm{h}$, and $350 \mathrm{~km} / \mathrm{h}$. 


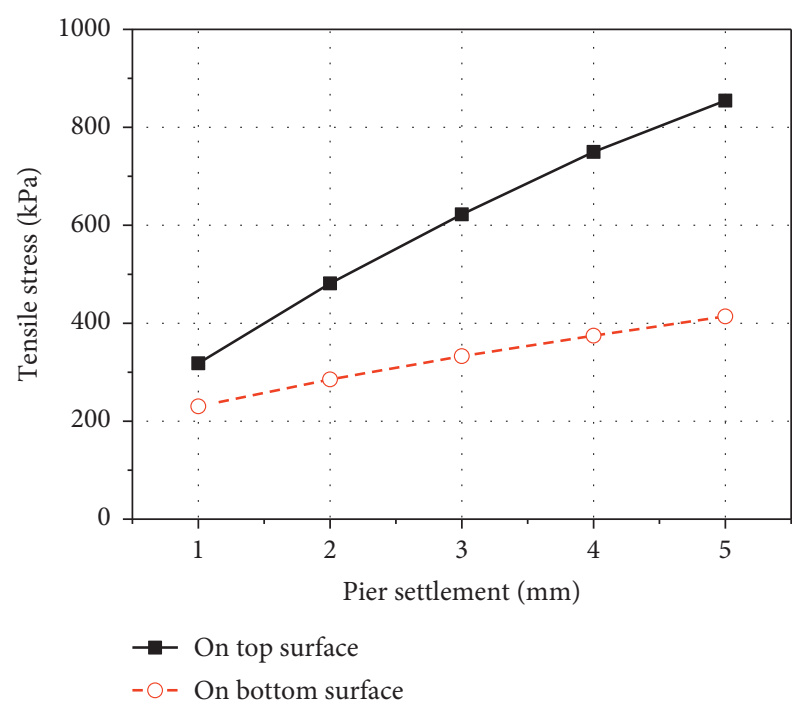

(a)

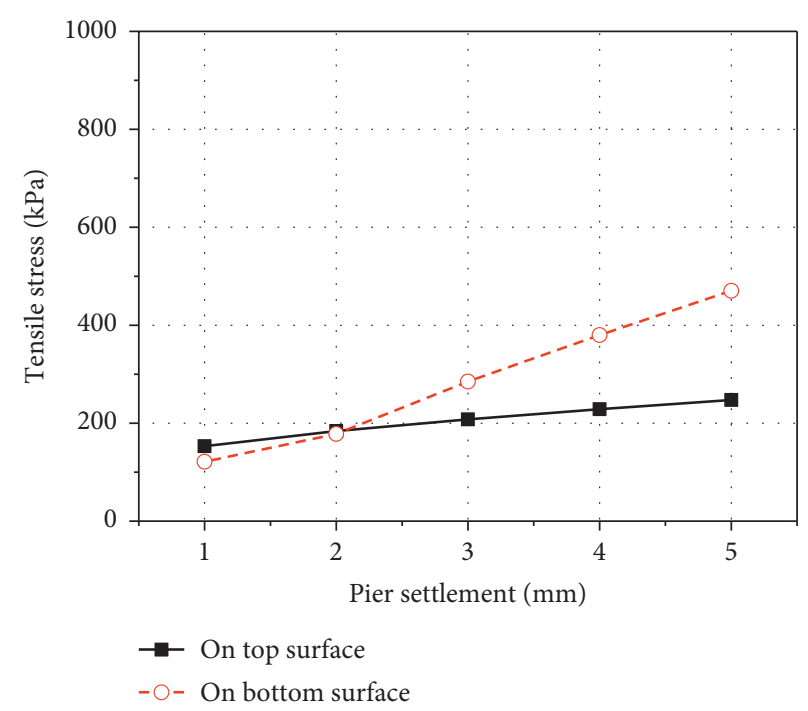

(b)

Figure 7: Additional static tensile stress at different locations subject to pier settlement: (a) slab and (b) base.

TABLE 2: Parameters of the train.

\begin{tabular}{lcc}
\hline Item & Value & Unit \\
\hline Distance between bogie centers & 17.5 & $\mathrm{~m}$ \\
Bogie wheelbase & 2.5 & $\mathrm{~m}$ \\
Wheel rolling circle diameter & 0.86 & $\mathrm{~m}$ \\
Car body mass & 33.766 & $\mathrm{t}$ \\
Bogie frame mass & 2400 & $\mathrm{~kg}$ \\
Wheelset mass & 1850 & $\mathrm{~kg}$ \\
Inertia moment of car body & 1654.5 & $\mathrm{t} \cdot \mathrm{m}^{2}$ \\
Inertia moment of bogie frame & 1314 & $\mathrm{~kg} \cdot \mathrm{m}^{2}$ \\
Inertia moment of wheelset & 123 & $\mathrm{~kg} \cdot \mathrm{m}^{2}$ \\
Primary suspension stiffness & 1.176 & $\mathrm{MN} / \mathrm{m}$ \\
Secondary suspension stiffness & 0.26 & $\mathrm{MN} / \mathrm{m}$ \\
\hline
\end{tabular}

Figure 8 illustrates the spatial distribution of additional structural stress along the lateral direction subject to the combined effect of pier settlement and running train. The figure is divided into three areas according to the distance from center line of track: (a) Area I covers the range from center line of track to rail; (b) Area II covers the range from rail to the slab-edge; and (c) Area III covers the range from slab-edge to base-edge. For structural stresses on surfaces of slab, the longer the distance from center line of track is, the larger the stresses in Area I are, and the smaller the stresses in Area II are. The maximum stress appears at the rail location where the train load is applied. As for the additional stress of base, the stresses increase slightly with the increment of distance from track center line in Area I and Area II. Meanwhile, in Area III, the stress on the top surface of base decreases and that on the bottom surface increases due to the friction effect between base and deck.

Figure 9 shows the dynamic additional tensile stresses at different locations when train is running through. As seen from the figure, the tensile stress on the top surface of slab is the largest, while the growth rate of stress on the top surface of base is the largest, which reaches $286.4 \%$. Compared to the structural stresses induced by pier settlement, the tensile stresses caused by running train are nonnegligible. When the train is running through the adjacent pier, the tensile stresses of slab and base are larger than those when the train is running through the settlement pier. This also indicates that the slightly upward movement of LCT at adjacent pier location has a great influence on the stability of LCT subject to the combined effects of pier settlement and running train.

Furthermore, the dynamic tensile stresses caused by running train at different speeds are displayed in Figure 10, where the fitting expressions of tensile stresses on top surface of slab and on bottom surface of base are given. As clearly seen from the results, the tensile stresses of LCT increase approximately linearly with the increment of pier settlement value. The calculated tensile stresses of slab and base with settlement of $5 \mathrm{~mm}$ are $1.23 \mathrm{MPa}$ and $0.83 \mathrm{MPa}$, respectively. Compared to the tensile strengths of slab and base, the safe margins of concrete slab and base are enough subject to running train and pier settlement.

Also, the evaluation of stability of LCT with larger pier settlement is performed, as seen in Figure 10. The larger the settlement value is, the larger the stresses are. Meanwhile, 


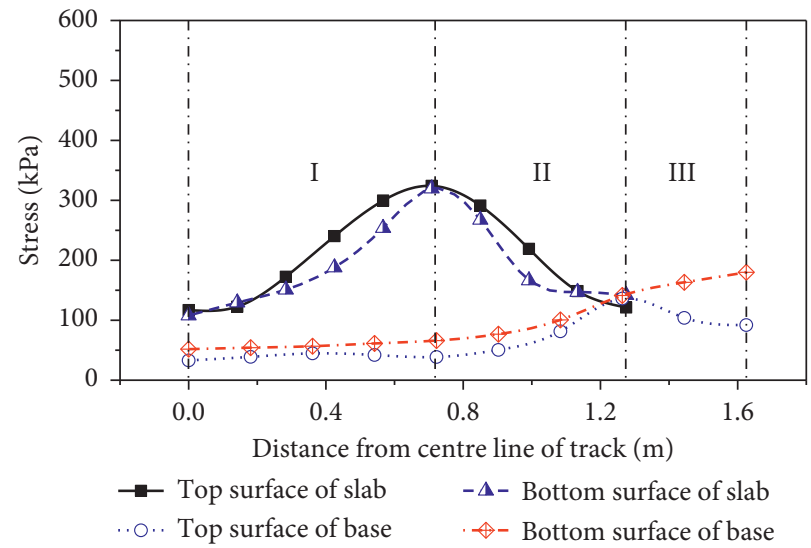

FIgURE 8: Spatial distribution of dynamic structural stress along the lateral direction.

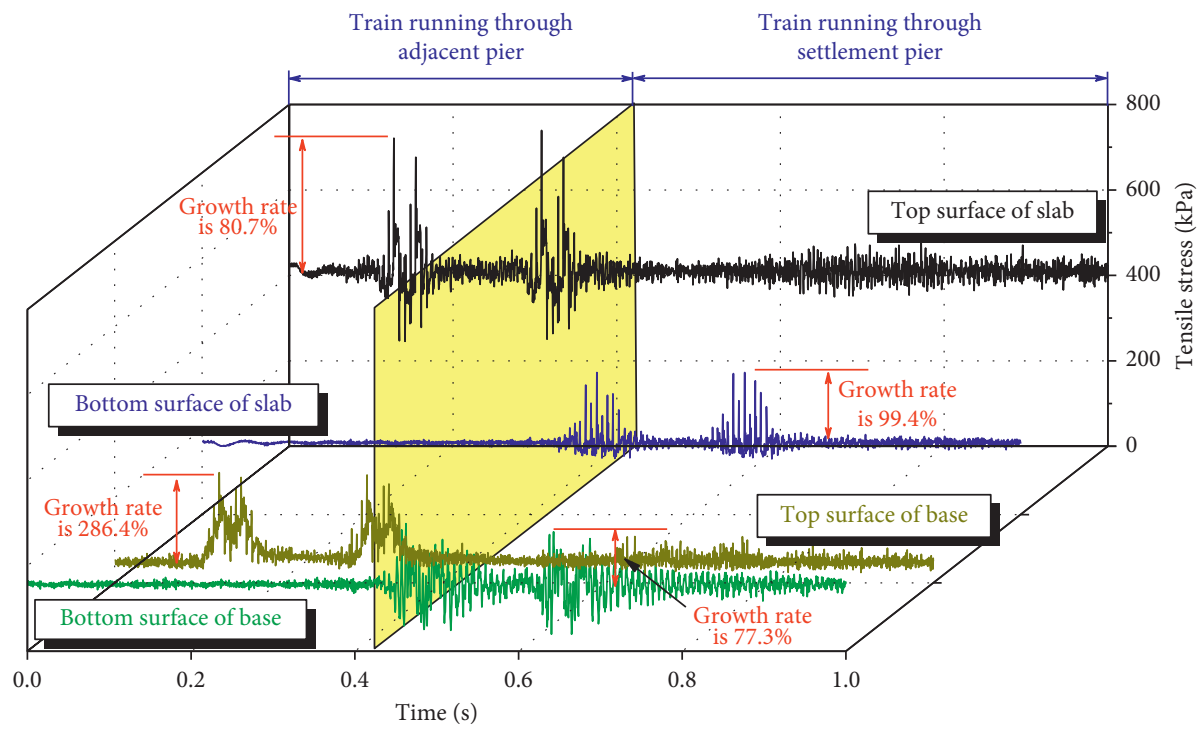

Figure 9: Dynamic additional tensile stresses at different locations when train is running through.
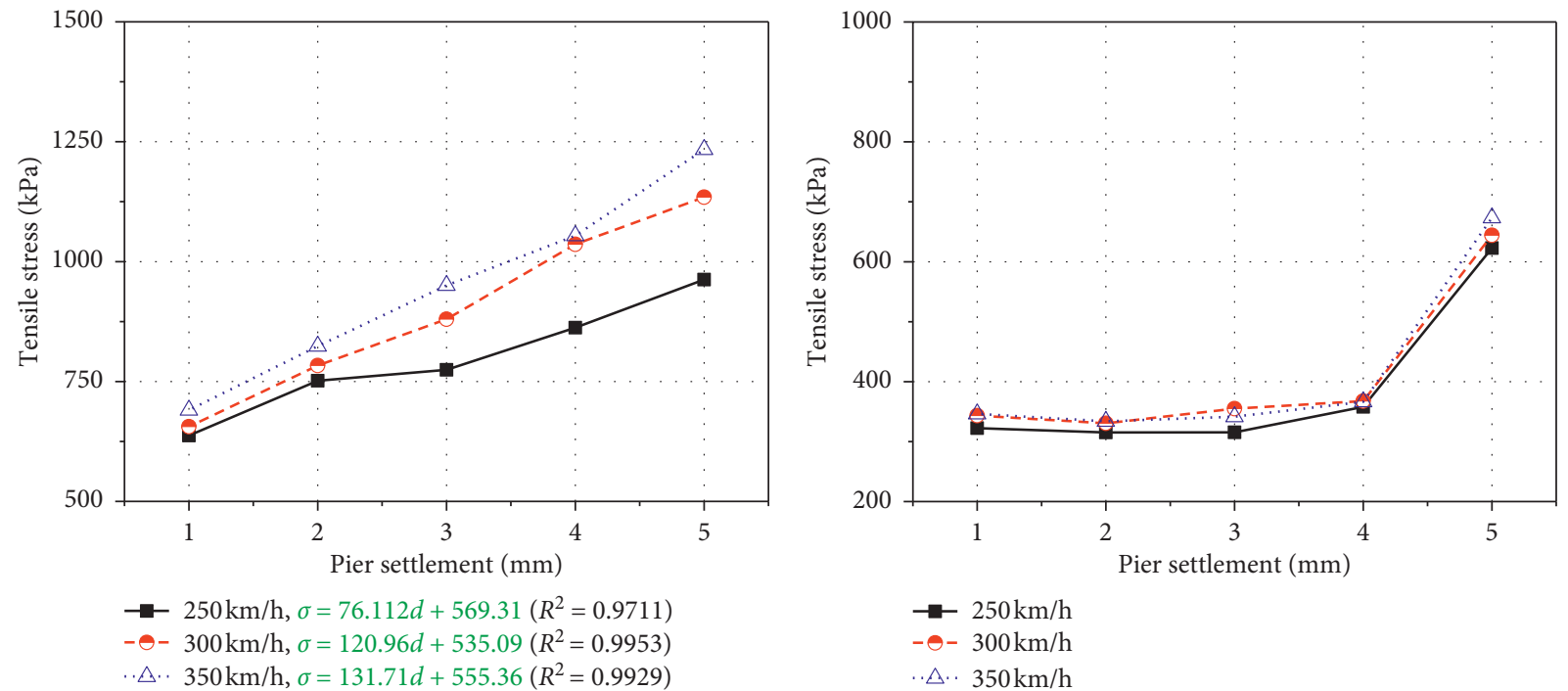

$250 \mathrm{~km} / \mathrm{h}, \sigma=76.112 d+569.31\left(R^{2}=0.9711\right)$

-๑- $300 \mathrm{~km} / \mathrm{h}, \sigma=120.96 d+535.09\left(R^{2}=0.9953\right)$

$\triangle \triangle .350 \mathrm{~km} / \mathrm{h}, \sigma=131.71 d+555.36\left(R^{2}=0.9929\right)$

(a)

FIgURE 10: Continued. 


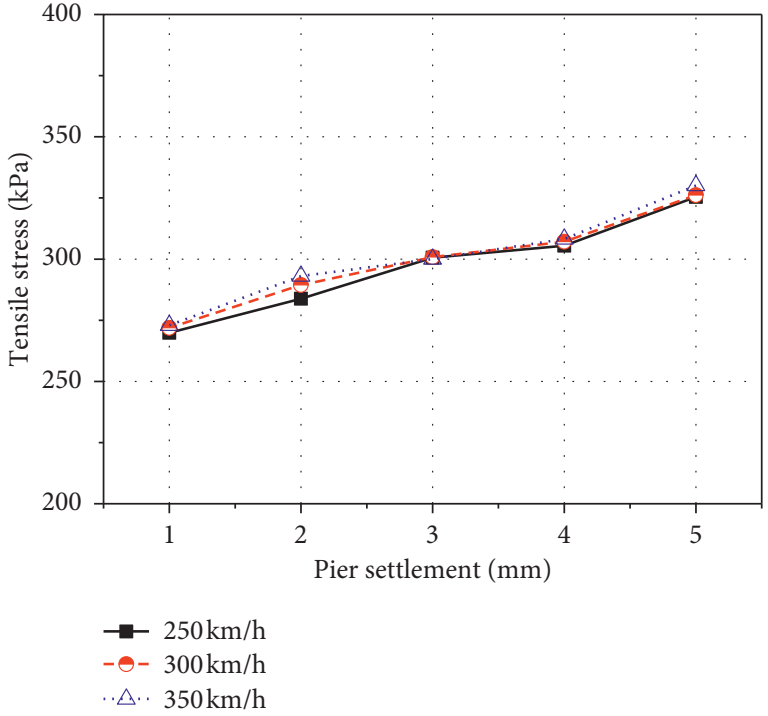

(c)

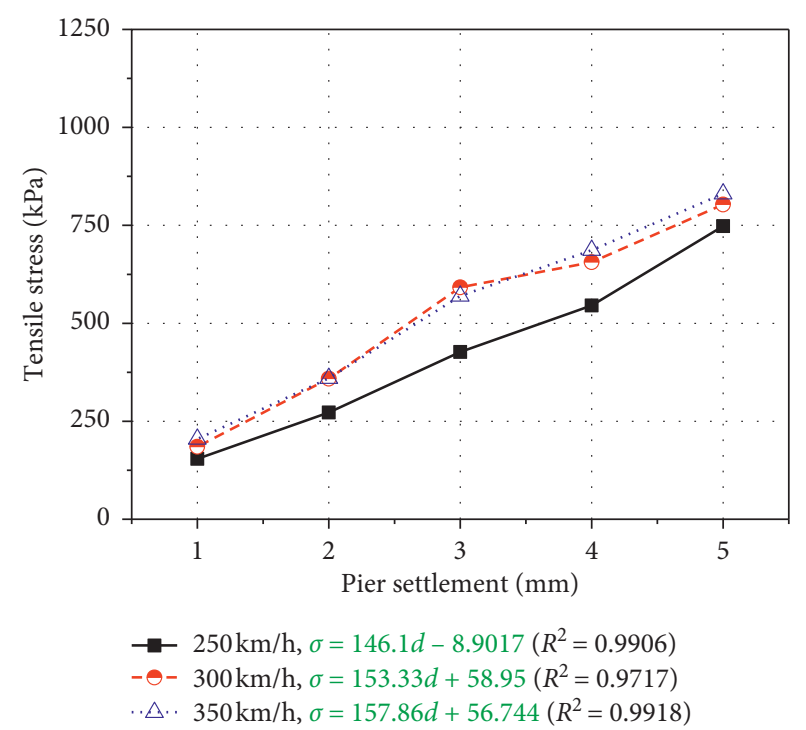

(d)

FIGURE 10: Dynamic tensile stresses of LCT caused by running train at different speeds: (a) top surface of slab, (b) bottom surface of slab, (c) top surface of base, and (d) bottom surface of base.

with the increase of running speed, the stresses increase slightly. Based on the fitting expressions in Figure 10, the critical pier settlement is determined to be $10.5 \mathrm{~mm}$ from dynamic perspective. Hence, to ensure the stability of LCT and running performance of train, the pier settlement is suggested to be less than $10.5 \mathrm{~mm}$ from the static and dynamic perspectives in practical engineering.

\section{Conclusions}

This work has investigated the influence of pier settlement on additional structural stress of longitudinal connected track. First, the generation mechanism of additional structural stress of LCT caused by pier settlement has been described in detail. On this basis, the deformation of LCT caused by pier settlement is analytically deduced and a dynamic model of high-speed train-LCT-bridge coupled system considering pier settlement has been established based on the train-track-bridge dynamic interaction theory, adopting which the additional structural stresses of LCT have been discussed from static and dynamic perspective. Some important conclusions are reached as follows:

(1) Pier settlement has a great influence on the stability of longitudinal connected track.

(2) Additional tensile stresses appear at three locations, that is, settlement pier location and two adjacent pier locations. Tensile stresses on top surface of slab and on bottom surface of base should be paid attention to.

(3) The downward deformation of LCT at the settlement pier location is much larger than the upward movement at the adjacent pier locations; however, the structural stresses at these locations are almost the same. This indicates that the behaviors of track structures at adjacent pier locations cannot be ignored in studying the influence of pier settlement on the system.

(4) To ensure the stability of LCT and running performance of train, the pier settlement is suggested to be less than $10.5 \mathrm{~mm}$ from the static and dynamic perspectives in practical engineering.

\section{Data Availability}

No data were used to support this study.

\section{Conflicts of Interest}

The authors declare that there are no conflicts of interest regarding the publication of this paper.

\section{Acknowledgments}

This work was supported by the Basic Natural Science and Frontier Technology Research Program of the Chongqing Municipal Science and Technology Commission (Grant no. cstc2019jcyj-msxmX0777), the State Grid Chongqing Electric Power Company Zikong Science and Technology Project (Grant no. 2020-01).

\section{References}

[1] Z. Chen, "Evaluation of longitudinal connected track under combined action of running train and long-term bridge deformation," Journal of Vibration and Control, vol. 26, no. 7-8, pp. 599-609, 2019.

[2] W. Zhai, H. Xia, C. Cai et al., "High-speed train-track-bridge dynamic interactions-part I: theoretical model and numerical simulation," International Journal of Rail Transportation, vol. 1, no. 1-2, pp. 3-24, 2013. 
[3] Z. Chen, W. Zhai, C. Cai, and Y. Sun, "Safety threshold of high-speed railway pier settlement based on train-trackbridge dynamic interaction," Science China Technological Sciences, vol. 58, no. 2, pp. 202-210, 2015.

[4] L. Sun, L. Chen, and H. H. Zelelew, "Stress and deflection parametric study of high-speed railway CRTS-II ballastless track slab on elevated bridge foundations," Journal of Transportation Engineering, vol. 139, no. 12, pp. 1224-1234, 2013.

[5] P. Wang, J. J. Ren, R. Xiang, and X. Y. Liu, "Influence of rubplate length on forces and displacements of longitudinally coupled slab track for a bridge turnout," Proceedings of the Institution of Mechanical Engineers, Part F: Journal of Rail and Rapid Transit, vol. 226, no. 3, pp. 284-293, 2012.

[6] M. Tarifa, X. Zhang, G. Ruiz, and E. Poveda, "Full-scale fatigue tests of precast reinforced concrete slabs for railway tracks," Engineering Structures, vol. 100, pp. 610-621, 2015.

[7] S. Zhu and C. Cai, "Interface damage and its effect on vibrations of slab track under temperature and vehicle dynamic loads," International Journal of Non-linear Mechanics, vol. 58, pp. 222-232, 2014.

[8] W. Powrie, L. A. Yang, and C. R. I. Clayton, "Stress changes in the ground below ballasted railway track during train passage," Proceedings of the Institution of Mechanical Engineers, Part F: Journal of Rail and Rapid Transit, vol. 221, no. 2, pp. 247-262, 2007.

[9] Z. Chen, W. Zhai, and Q. Yin, "Analysis of structural stresses of tracks and vehicle dynamic responses in train-track-bridge system with pier settlement," Proceedings of the Institution of Mechanical Engineers, Part F: Journal of Rail and Rapid Transit, vol. 232, no. 2, pp. 421-434, 2018.

[10] Z. W. Chen, Y. Sun, and W. M. Zhai, "Mapping relationship between pier settlement and rail deformation of high-speed railways-part (II): the longitudinal connected ballastless track system," SCIENTIA SINICA Technologica, vol. 44, no. 7, pp. 778-785, 2014, in Chinese.

[11] M. Brenschede, Parameter studies on the dynamic behavior of slab track system, Ph.D Thesis, Techische Unicersitat Munchen, Munich, Germany, 2002.

[12] C. Esveld, Modern Railway Track, TU Delft Press, Delft, Netherlands, 2001.

[13] S.-T. Yen and Y.-H. Lee, "Parameter identification and analysis of a slab track system using 3D ABAQUS program," Journal of Transportation Engineering, vol. 133, no. 5, pp. 288-297, 2007.

[14] W. Zhai and X. Sun, "A detailed model for investigating vertical interaction between railway vehicle and track," Vehicle System Dynamics, vol. 23, no. sup1, pp. 603-615, 1994.

[15] Z. Zhang, S. Wei, B. Andrawes, D. A. Kuchma, and J. R. Edwards, "Numerical and experimental study on dynamic behaviour of concrete sleeper track caused by wheel flat," International Journal of Rail Transportation, vol. 4, no. 1, pp. 1-19, 2016.

[16] J. A. Priest, W. Powrie, L. Yang, P. J. Grabe, and C. R. I. Clayton, "Measurements of transient ground movements below a ballasted railway line," Géotechnique, vol. 60, no. 9, pp. 667-677, 2010.

[17] Z. Chen and H. Fang, "Dynamic evaluation of elastic bar in track transition section of fast-metro system," Advances in Mechanical Engineering, vol. 11, no. 12, Article ID 1687814019895740, 2019.

[18] W. Zhai, Z. Han, Z. Chen, L. Ling, and S. Zhu, "Train-trackbridge dynamic interaction: a state-of-the-art review," Vehicle System Dynamics, vol. 57, no. 7, pp. 984-1027, 2019.
[19] L. Xu, Z. Yu, and C. Shi, "A matrix coupled model for vehicleslab track-subgrade interactions at 3-D space," Soil Dynamics and Earthquake Engineering, vol. 128, Article ID 105894, 2020. 